\title{
Left Ventricular Apical Thrombus Mimicking Hypertrabeculation
}

\author{
Ikuo Misumi ${ }^{1}$, Koji Sato ${ }^{1}$, Miwa Nagano ${ }^{1}$, Masahiro Obata ${ }^{2}$, Joji Urata ${ }^{3}$, Hiroki Usuku ${ }^{4}$, \\ Koichi Kaikita ${ }^{4}$ and Kenichi Tsujita ${ }^{4}$
}

\begin{abstract}
:
A 73-year-old man visited our hospital due to dyspnea and epigastralgia. His plasma brain natriuretic peptide level was $1,205 \mathrm{pg} / \mathrm{mL}$. A 12-lead electrocardiogram showed ST segment depression in leads I, V5, and V6. Transthoracic echocardiography showed dilatation and severe hypokinesis of the left ventricle. Hypertrabeculation was observed at the septum, apex, and lateral wall. Delayed enhancement of cardiac magnetic resonance imaging revealed a relatively low uptake of contrast agent at a large apical trabecula. After treatment with diuretics, follow-up echocardiography showed the disappearance of the controversial apical trabecula, which was later confirmed to have been a thrombus.
\end{abstract}

Key words: left ventricular noncompaction, left ventricular thrombus mimicking hypertrabeculation, cardiac magnetic resonance imaging

(Intern Med 60: 2245-2250, 2021)

(DOI: 10.2169/internalmedicine.6482-20)

\section{Introduction}

Left ventricular noncompaction (LVNC) is a new and unclassified cardiomyopathy. It is characterized by increased left ventricular (LV) trabeculation and the presence of intertrabecular recesses communicating with the LV cavity (1).

We encountered a case of LV dysfunction complicated by apical LVNC, wherein a large apical trabecula disappeared following treatment for heart failure.

\section{Case Report}

A 73-year-old man visited our hospital due to dyspnea and epigastralgia with a history of daily alcohol consumption of $1 \mathrm{~L}$ of beer and $100 \mathrm{~mL}$ of distilled spirits. He had no personal or family history of LVNC, other cardiac disease, or neuromuscular disease.

On a physical examination, his blood pressure and pulse rate were $119 / 77 \mathrm{mmHg}$ and 88 beats per minute, respectively. Auscultation revealed third and fourth apical heart sounds. The blood oxygen saturation level measured by a pulse oximeter was $94 \%$.

A blood analysis revealed impairment of the hepatic and renal functions. His International Normalized ratio of prothrombin time, activated partial thromboplastin time, and plasma D-dimer level were 1.91, 32 seconds, and $13.6 \mathrm{ng} /$ $\mathrm{mL}$, respectively. His plasma brain natriuretic peptide (BNP) level was $1,205 \mathrm{pg} / \mathrm{mL}$.

Gastroscopy revealed an acute gastric mucosal lesion (AGML) that spread with oozing blood (Fig. 1). A 12-lead electrocardiogram demonstrated left atrial enlargement and ST segment depression in leads I, V5, and V6 (Fig. 2a), and chest radiography showed bilateral pleural effusion (Fig. 2b). Furthermore, dilatation and severe hypokinesis of the left ventricle ( $\mathrm{LV}$ end-diastolic dimension of $67 \mathrm{~mm}$, end-systolic dimension of $59 \mathrm{~mm}$, and ejection fraction of $28 \%$ ) were observed on transthoracic echocardiography (Fig. 3). The LV wall thickness was normal (interventricular septum and posterior wall thickness was 10 and $9 \mathrm{~mm}$, respectively). Hypertrabeculation was observed at the septum, apex, and lateral wall (Fig. 4, arrows and arrowheads). The

\footnotetext{
${ }^{1}$ Department of Cardiology, Kumamoto City Hospital, Japan, ${ }^{2}$ Department of Gastroenterology and Hepatology, Kumamoto City Hospital, Japan, ${ }^{3}$ Department of Radiology, Kumamoto City Hospital, Japan and ${ }^{4}$ Department of Cardiovascular Medicine, Kumamoto University School of Medicine, Japan

Received: October 12, 2020; Accepted: January 6, 2021; Advance Publication by J-STAGE: February 22, 2021

Correspondence to Dr. Ikuo Misumi, misumi_ikuo@yahoo.co.jp
} 
size of the large apical trabecula was $19 \times 12 \mathrm{~mm}$ during diastole (Fig. 4, arrow). The apical trabecula had high echogenicity and an immobile structure and made contact with other trabeculae during the cardiac cycle, suggesting it was made of myocardium.

Pulsed-wave Doppler echocardiography at the mitral inflow showed an $\mathrm{E}$ wave, $\mathrm{A}$ wave, and $\mathrm{E}$ wave deceleration time of $72 \mathrm{~cm} / \mathrm{s}, 35 \mathrm{~cm} / \mathrm{s}$, and $155 \mathrm{~ms}$, respectively. Pulsedwave tissue Doppler echocardiography at the septal mitral annulus showed an e' wave of $3.6 \mathrm{~cm} / \mathrm{s}$ and E/e' ratio of 20.1. Continuous-wave Doppler echocardiography at tricuspid regurgitation showed an estimated peak pressure gradient of $46 \mathrm{mmHg}$. Color-flow imaging showed mild mitral regurgitation. Cardiac magnetic resonance (CMR) imaging

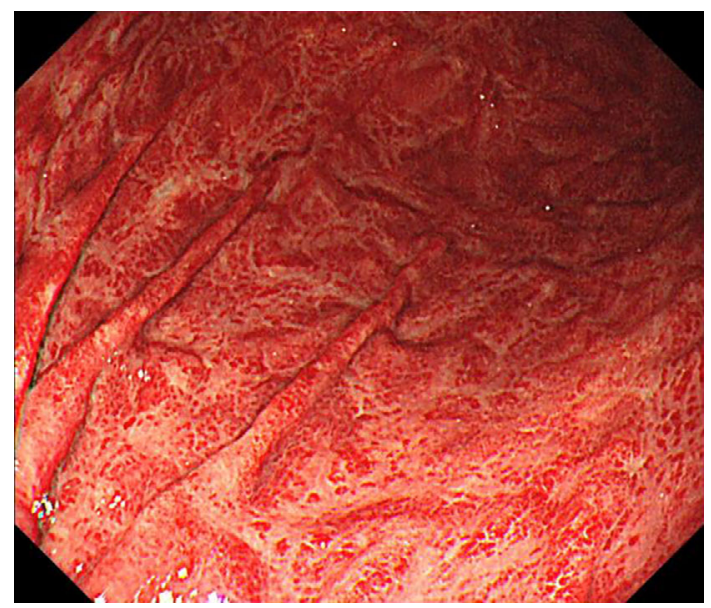

Figure 1. Gastroscopy revealed an acute gastric mucosal lesion that spread with oozing blood. also showed hypertrabeculation at the septum, apex, and lateral wall (Fig. 5, arrow and arrowheads) with the distinct apical trabecula $(19 \times 8 \mathrm{~mm})$ (Fig. 5, arrow). However, there was a relatively low uptake of contrast agent at this trabecula on delayed enhancement (DE)-CMR, suggesting it might not be a cardiac structure (Fig. 5, arrow) (2).

The patient was admitted to our hospital and treated with furosemide, spironolactone, imidapril, and lansoprazole. Twenty days later, follow-up two-dimensional transthoracic echocardiography showed that the apical trabecula had almost disappeared (Fig. 6, asterisk) without any marked change in the LV wall motion. However, hypertrabeculation was still observed at the septum and the lateral wall, where the criteria for LVNC established by Chin et al. (3) and Jenni et al. (4) were fulfilled (Table) (Fig. 6, arrowheads). Continuous-wave Doppler echocardiography showed that the estimated pressure gradient at tricuspid regurgitation decreased to $27 \mathrm{mmHg}$. Blood analyses revealed improved transaminase (aspartate aminotransferase: from 138 to 50 IU/L) and BNP (from 1,205 to $453 \mathrm{pg} / \mathrm{mL}$ ) levels (Fig. 7). Follow-up gastroscopy showed that the AGM was healed. Due to the appearance of drug-related skin rashes, drugs were suspended barring the initiation of Nexium (Fig. 7).

Forty days later, the plasma D-dimer levels had decreased to $2.0 \mathrm{ng} / \mathrm{mL}$. DE-CMR showed that the apical thrombus had markedly diminished to $10 \times 8 \mathrm{~mm}$ (Fig. 8, arrow). Hypertrabeculation at the septum and lateral wall also met the criteria for LVNC established by Petersen et al. (5) (Table). Cardiac catheterization showed no significant coronary artery stenosis (Fig. 9). Hemodynamic data obtained using the Swan-Ganz catheter showed Forrester subset IV cardiac dysfunction (pulmonary artery wedge pressure of $25 \mathrm{mmHg}$ and (a)

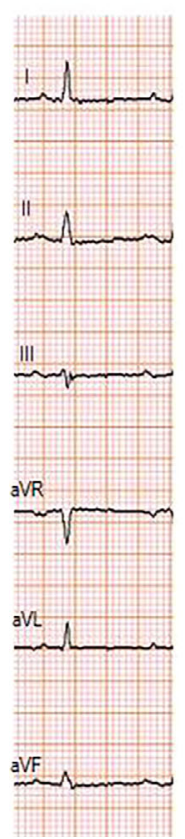

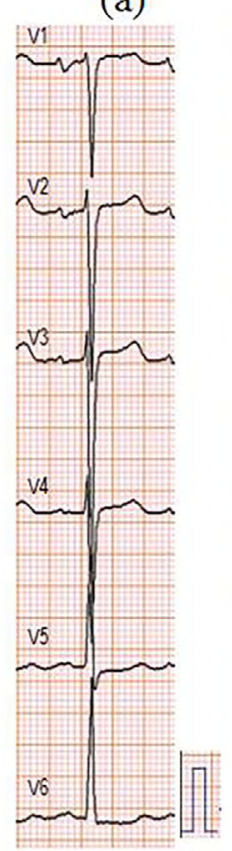

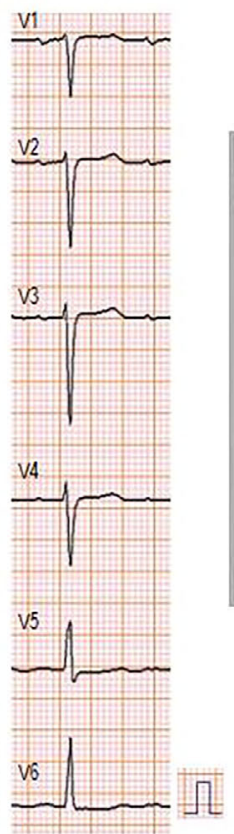

(b)

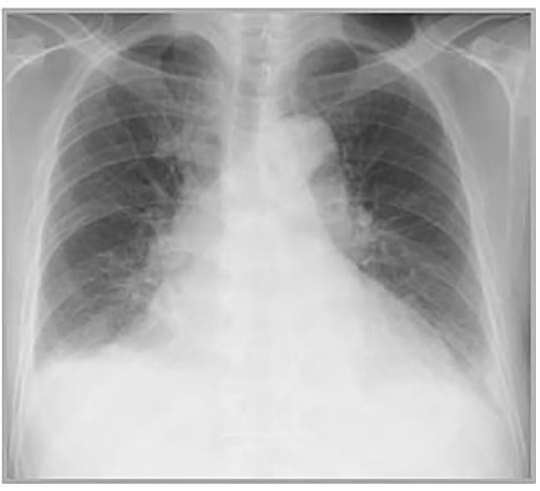

Figure 2. a: A 12-lead electrocardiogram shows left atrial enlargement and ST segment depression in leads I, V5, and V6. b: A chest radiograph shows bilateral pleural effusion. 


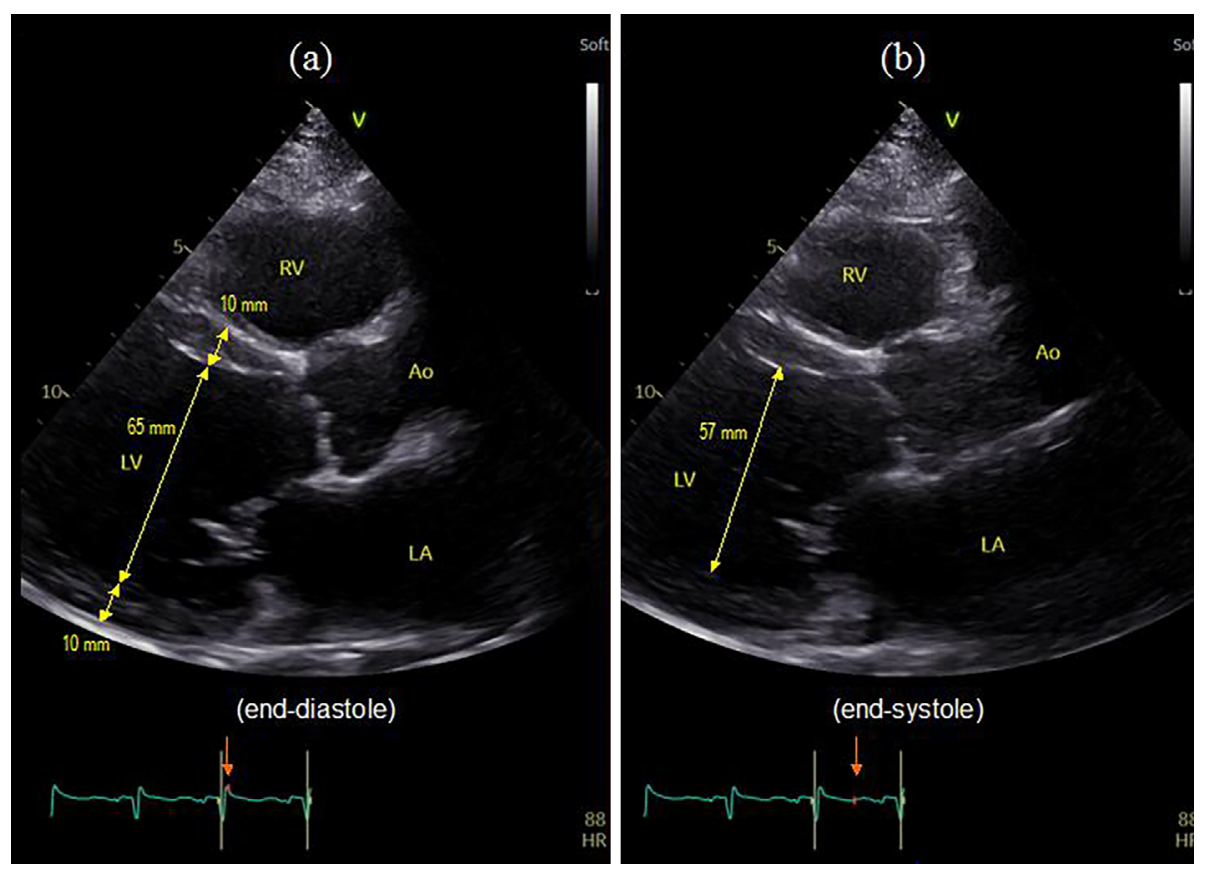

Figure 3. The transthoracic parasternal long-axis view during diastole (a) and systole (b) shows dilatation and severe hypokinesis of the left ventricle ( $\mathrm{LV}$ end-diastolic dimension: $67 \mathrm{~mm}$, end-systolic dimension: $59 \mathrm{~mm}$, and ejection fraction: $28 \%$ ). The interventricular septum and posterior wall thicknesses were 10 and $9 \mathrm{~mm}$, respectively.
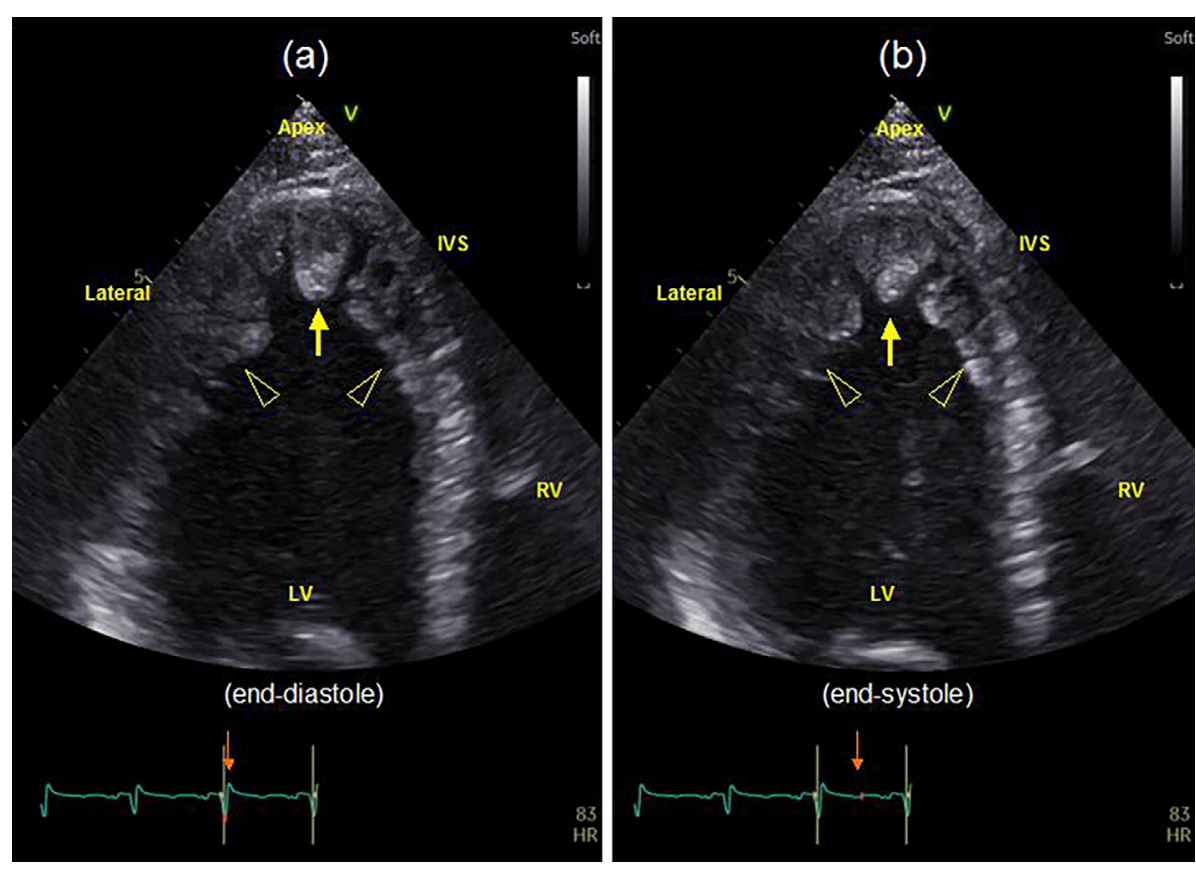

Figure 4. The apical long-axis view during diastole (a) and systole (b) shows apical hypertrabeculation (arrows and arrowheads). The large apical trabecula measured $19 \times 12 \mathrm{~mm}$ (a, arrow).

cardiac index of $2.18 \mathrm{~L} / \mathrm{min} / \mathrm{m}^{2}$ ).

The patient was discharged on heart failure medication, and follow-up was scheduled.

\section{Discussion}

The pathophysiology of LV hypokinesis in this patient is unclear. As coronary angiography showed no organic stenosis, the possible causes of hypokinesis include dilated cardi- 


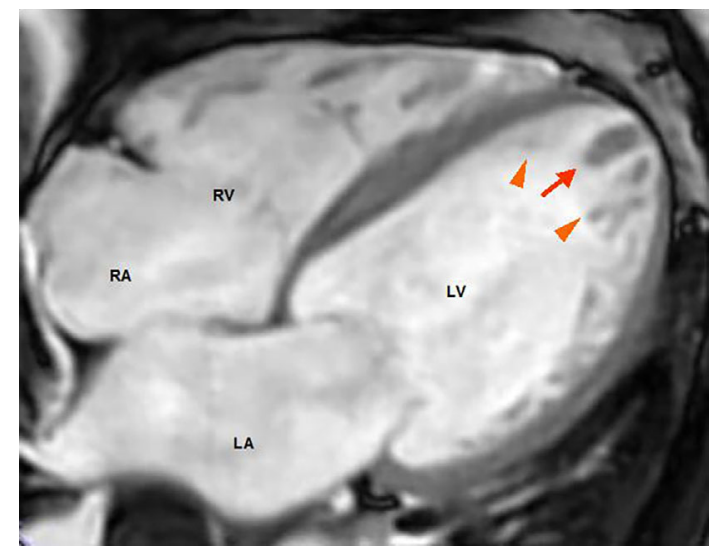

Figure 5. Cardiac magnetic resonance imaging shows apical hypertrabeculation. The uptake of contrast agent appears low (arrow). omyopathy (6) due to alcoholism or idiopathic causes.

In the present case, hypertrabeculation at the septum and lateral wall met the main criteria for LVNC established by Chin et al., Jenni et al., and Petersen et al. LVNC may be not only embryogenic but also acquired, including manifestations in young athletes, pregnant women, sickle cell anemia, and cardiomyopathy. As the present case had no personal or family history, LVNC might have been caused secondary to dilated cardiomyopathy.

At the apex, there was a large thrombus that appeared to be a trabecula on transthoracic echocardiography. The appearance of LV thrombus on transthoracic echocardiography has been reported to be variable and to depend on its age (7). For example, recent or actively forming thrombi may be echo-lucent, highly mobile, and disposed to protrude into the cavity. Older thrombi generally have a smooth surface and are sessile, laminated, and organized with higher
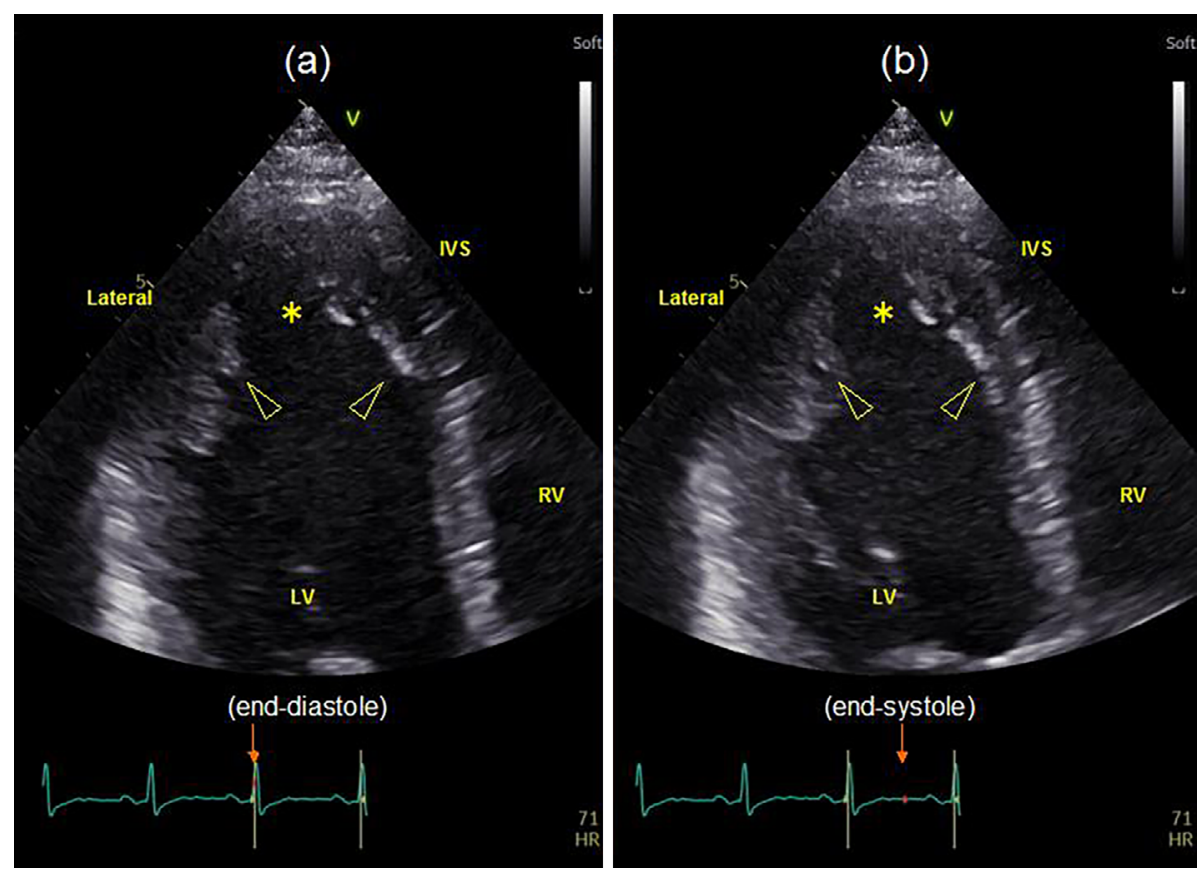

Figure 6. Twenty days later, follow-up two-dimensional transthoracic echocardiography during diastole (a) and systole (b) indicated the disappearance of the apical trabecula (arrowheads).

Table. Diagnostic Criteria for Left Ventricular Noncompaction.

\begin{tabular}{l}
\hline 1. Reference 3 \\
Prominent trabeculations wit deep recesses \\
Ratio of $\mathrm{X} / \mathrm{Y} \leq 0.5$ in end-diastole \\
(X=distance from the epicardial surface to the trough of the trabecular recess, $\mathrm{Y}=$ distance from the \\
epicardial surface to peak of trabeculation) \\
\hline 2. Reference 4 \\
A two-layer structure, with a thin compacted layer and a thick non-compacted layer \\
Ratio of NC/C $>2$ in end-systole \\
\hline 3. Reference 5 \\
Presence of marked trabeculations and deep intertrabecular recesses within the noncompacted layer \\
Ratio of NC/C $>2.3$ with $\mathrm{CMR}$ in end-diastole
\end{tabular}

NC: non-compacted layer, C: compacted layer, CMR: cardiac magnetic resonance imaging 
echogenicity than the LV wall. In patients with LVNC, LV thrombus may occasionally be observed within the trabeculations or at the recesses where blood flow is sluggish (8). Transthoracic echocardiography usually shows mobile and homogeneous echodense structures. In the present case, however, LV thrombus was observed at the apex where LVNC was absent. Furthermore, it was not mobile or echolucent but had figure of trabecula comparable to adjacent trabeculae.

DE-CMR revealed that the apical trabecula-like structure had low enhancement compared with other trabeculae, suggesting it was made of a thrombus. Forty days later, CMR

\begin{tabular}{|c|c|c|c|c|}
\hline & & $\begin{array}{c}\text { On } \\
\text { admission }\end{array}$ & $\begin{array}{c}20 \text { days } \\
\text { later }\end{array}$ & $\begin{array}{c}40 \text { days } \\
\text { later }\end{array}$ \\
\hline $\begin{array}{l}\text { Blood analysis } \\
\text { D-dimer } \\
\text { BNP } \\
\text { AST } \\
\text { ALT }\end{array}$ & $\begin{array}{l}(\mathrm{ng} / \mathrm{mL}) \\
(\mathrm{pg} / \mathrm{mL}) \\
(\mathrm{IU} / \mathrm{L}) \\
(\mathrm{IU} / \mathrm{L})\end{array}$ & $\begin{array}{l}13.6 \\
1205 \\
138 \\
102\end{array}$ & $\begin{array}{l}453 \\
50 \\
55\end{array}$ & $\begin{array}{l}2.0 \\
605 \\
31 \\
22\end{array}$ \\
\hline $\begin{array}{l}\text { Cardiac MR } \\
\text { Hypertrabea } \\
\text { thrombus at }\end{array}$ & $\begin{array}{l}\text { ation or } \\
\text { e apex }\end{array}$ & $(+)$ & & $(-)$ \\
\hline $\begin{array}{l}\text { Echocardiograp } \\
\text { Hypertrabea } \\
\text { thrombus at } \\
\text { LVEF } \\
\text { TRPG }\end{array}$ & $\begin{array}{l}y \\
\text { ation or } \\
\text { e apex } \\
(\%) \\
(\mathrm{mmHg})\end{array}$ & $\begin{array}{l}(+) \\
24 \\
46\end{array}$ & $\begin{array}{l}(-) \\
20 \\
27\end{array}$ & $\begin{array}{l}(-) \\
22 \\
46\end{array}$ \\
\hline$\frac{\text { Gastrofiberscop }}{A G M L}$ & & $(+)$ & $(-)$ & \\
\hline Drug rash & & & $(+)$ & $(-)$ \\
\hline $\begin{array}{l}\text { Medication } \\
\text { Furosemide } \\
\text { Spironolactor } \\
\text { Imidapril } \\
\text { Lansoprazole } \\
\text { Nexium }\end{array}$ & & $\begin{array}{l}(x) \\
(x) \\
(x) \\
(x) \\
(x)\end{array}$ & $\begin{array}{l}? \\
? \\
\bullet \\
\text { (x) }\end{array}$ & $\begin{array}{l}(x) \\
(x) \\
(x) \\
(x) \\
\end{array}$ \\
\hline
\end{tabular}

Figure 7. Time course of laboratory findings and treatments. On admission, a blood analysis showed a high plasma D-dimer level, brain natriuretic peptide level, and liver dysfunction. Cardiac magnetic resonance imaging and echocardiography showed hypertrabeculation that disappeared with the improvement of the laboratory data. showed that the apical structure had markedly decreased in size. During this period, the patient did not complain of any signs of embolism or undergo CT to detect embolism.

Anticoagulant therapy has not been performed thus far, as LV trabeculation was not excluded, hemorrhagic AGML was present, and the PT-INR level was already elevated. It is possible that, in addition to LV hypokinesis, hypercoagulability following chronic liver dysfunction (9) or inflammation (10) might have caused LV thrombus formation. Anticoagulation therapy with edoxaban tosilate was started thereafter.

\section{Conclusions}

Left ventricular thrombus may come to resemble trabeculae in cases of LVNC. Diffuse left ventricular hypokinesis and hypercoagulability may contribute to this trabecula-like thrombus formation.

The authors state that they have no Conflict of Interest (COI).

\section{Acknowledgements}

I would like to thank Dr. Masahiro Obata for his wonderful

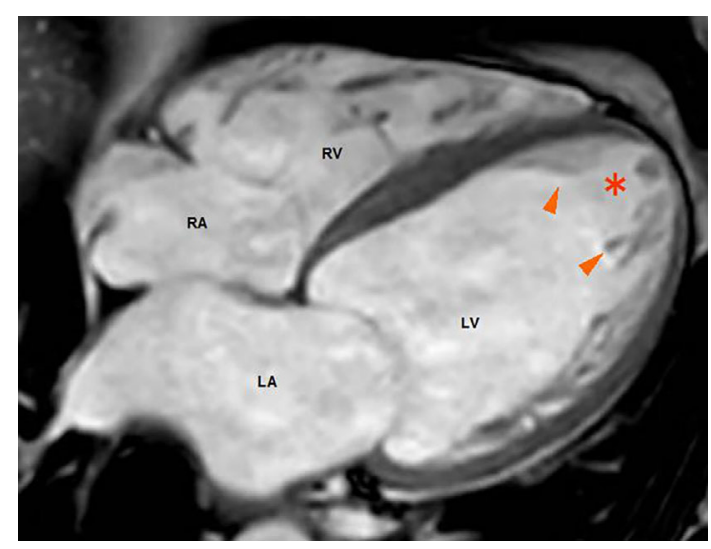

Figure 8. Cardiac magnetic resonance imaging (arrowheads) performed 40 days later confirmed the disappearance of the thrombus.

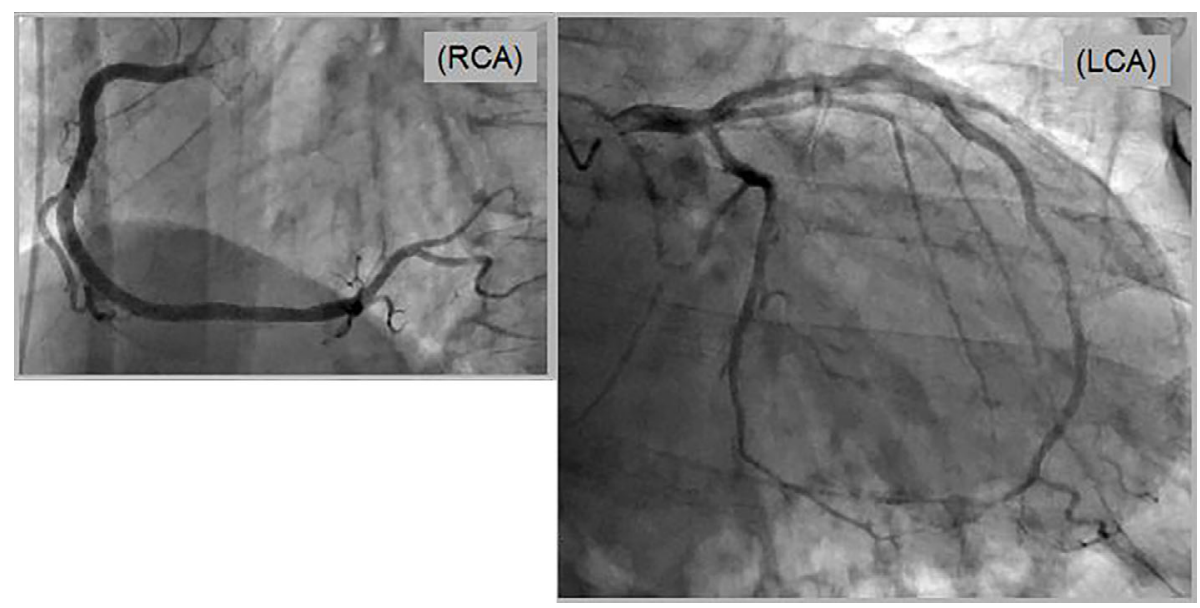

Figure 9. Cardiac catheterization shows no significant coronary artery stenosis. 
collaboration. He supported me greatly and was always willing to help me.

I would also like to thank Mr. Yoshiharu Saito and Ms. Mayumi Ueno for taking the echocardiographic images.

\section{References}

1. Arbustini E, Weidemann F, Hall JL. Left ventricular noncompaction: a distinct cardiomyopathy or a trait shared by different cardiac diseases? J Am Coll Cardiol 64: 1840-1850, 2014.

2. Delewi R, Zijlstra F, Piek JJ. Left ventricular thrombus formation after acute myocardial infarction. Heart 98: 1743-1749, 2012.

3. Chin TK, Perloff JK, Williams RG, Jue K, Mohrmann R. Isolated noncompaction of left ventricular myocardium. A study of eight cases. Circulation 82: 507-513, 1990.

4. Jenni R, Oechslin E, Schneider J, Attenhofer Jost C, Kaufmann PA. Echocardiographic and pathoanatomical characteristics of isolated left ventricular non-compaction: a step towards classification as a distinct cardiomyopathy. Heart 86: 666-671, 2001.

5. Petersen SE, Selvanayagam JB, Wiesmann F, et al. Left ventricular non-compaction: insights from cardiovascular magnetic reso- nance imaging. J Am Coll Cardiol 46: 101-105, 2005.

6. Hofer M, Stollberger C, Finsterer J. Acquired noncompaction associated with myopathy. Int J Cardiol 121: 296-297, 2007.

7. Turhan S, Ozcan OU, Erol C. Imaging of intracardiac thrombus. Cor et Vasa 55: e176-e183, 2013.

8. Aryal MR, Badal M, Giri S, Pradhan R. Left ventricular noncompaction presenting with heart failure and intramural thrombus. BMJ Case Rep 2013: bcr2013009757, 2013.

9. Tripodi A, Anstee QM, Sogaard KK, Primignani M, Valla DC. Hypercoagulability in cirrhosis: causes and consequences. J Thromb Haemost 9: 1713-1723, 2011.

10. Iba T, Levy JH. Inflammation and thrombosis: roles of neutrophils, platelets and endothelial cells and their interactions in thrombus formation during sepsis. J Thromb Haemost 16: 231$241,2018$.

The Internal Medicine is an Open Access journal distributed under the Creative Commons Attribution-NonCommercial-NoDerivatives 4.0 International License. To view the details of this license, please visit (https://creativecommons.org/licenses/ by-nc-nd/4.0/).

(C) 2021 The Japanese Society of Internal Medicine

Intern Med 60: 2245-2250, 2021 